\title{
Urinary electrolyte excretion, alcohol consumption, and blood pressure in the Scottish heart health study
}

\author{
W C S Smith, I K Crombie, R T Tavendale, S K Gulland, H D Tunstall-Pedoe
}

\begin{abstract}
As part of a study of risk factors for coronary heart disease 24 hour urine collections were obtained from 7354 men and women aged 40-59 selected at random from 22 districts throughout Scotland (Scottish heart health study). The mean of two standardised measurements of blood pressure was related to the reported consumption of alcohol and measurements of height, weight, pulse rate, and electrolyte excretion. Several significant correlations were found with both systolic and diastolic pressures, but only the coefficients for age, body mass index, and pulse rate were greater than $0 \cdot 1$. Alcohol consumption showed a weak positive correlation with blood pressure in men. Sodium excretion showed a weak positive correlation with blood pressure in both sexes, and potassium excretion showed weak negative correlations. In multiple regression analysis age, pulse rate, body mass index, alcohol consumption, and potassium excretion had significant independent effects but sodium excretion did not.

Although measuring blood pressure twice on one occasion and 24 hour urinary sodium excretion only once may have weakened any potential correlation, the most likely explanation of these results is that the relation between sodium and blood pressure in the population is weak and that potassium and alcohol are of greater importance.
\end{abstract}

\section{Introduction}

The relation between salt and blood pressure has been debated for the past century,' but despite many studies the issue is still unresolved. The debate is more than purely academic as means of non-pharmacological control of blood pressure are sought in an attempt to prevent stroke and coronary heart disease. 'There have been three main approaches to studying the relation between salt and blood pressure-namely, studies within communities comparing people's blood pressure with measures of their salt intake and excretion "; studies between communities analysing mean blood pressure and measures of salt intake across different groups or countries'; and studies altering the salt intake of individuals and examining the effect on blood pressure." Each approach has important problems, which new studies are trying to limit.

The main problems with studies of subjects in a community are the individual variations in blood pressure and salt intake and the narrow range of values. Several possible solutions have been suggested to limit these, including averaging several measurements of blood pressure and salt intake, and increasing the size of the study. ${ }^{x}$ The Scottish heart health study, which was set up to investigate the high mortality from coronary heart disease in Scotland and its geographical variation, is characterised by a large number of subjects; it measured 24 hour urinary salt excretion in an attempt to address the relation between salt intake and blood pressure while controlling for possible confounding factors.

\section{Subjects and methods}

The data were obtained from the Scottish heart health study." Subjects in the study were recruited from the lists of 10 general practitioners selected at random in each of 22 districts throughout Scotland; the target number for each district was 450 men and women aged 40-59. They were examined during 1984-6, and the overall response rate was $74 \%$.

Each subject completed a questionnaire, which included a seven day recall of assessment of alcohol consumption; had a physical examination, which included measurement of height, weight, blood pressure, and pulse rate; and was asked to make a 24 hour collection of urine. The measurement of blood pressure used was the mean of two readings taken with a random zero sphygmomanometer after the subject had been seated for five minutes. Two sizes of cuff were used depending on the subject's upper arm circumference, and each observer had standard training with monthly quality checks. ${ }^{10}$ Both systolic and diastolic (phase V) pressures were measured and used in the analysis. The urine collections were preserved with thymol; their completeness was assessed from their volume and from the subjects' reports. Potassium and sodium concentrations were estimated with a Beckman E2A electrolyte analyser and creatinine concentration with a Cobas Bio centrifugal fast analyser.

Subjects were included in the study if they had completed the questionnaire, had a physical examination and given a venous blood sample, and provided a 24 hour collection of urine; subjects taking antihypertensive treatment were excluded. Correlation and regression analyses were carried out.

\section{Results}

A total of 7354 subjects ( 3754 men and 3600 women) met the criteria for entry to this analysis. Altogether $17 \cdot 5 \%$ of the population of the Scottish heart health study were excluded, most because they failed to provide a urine collection; only $1 \cdot 6 \%$ were excluded because of antihypertensive treatment. Table I gives the mean values for the variables measured in the men and women. Table II shows the Pearson correlation

TABIE I-Mean values (SD) of variables measured in men and women

\begin{tabular}{lrr}
\hline & Men $(\mathrm{n}=3754)$ & Women $(\mathrm{n}=3600)$ \\
\hline Blood pressure $(\mathrm{mm} \mathrm{Hg}):$ & $133 \cdot 7(18 \cdot 7)$ & $130 \cdot 5(20 \cdot 1)$ \\
Systolic & $84 \cdot 3(11 \cdot 6)$ & $80 \cdot 9(11 \cdot 4)$ \\
$\quad$ Diastolic & $75 \cdot 7(13 \cdot 3)$ & $78 \cdot 4(12 \cdot 2)$ \\
Pulse rate $($ beats $\mathrm{min})$ & $173 \cdot 1(6 \cdot 8)$ & $160 \cdot 2(6 \cdot 0)$ \\
Height $(\mathrm{cm})$ & $78 \cdot 1(11 \cdot 6)$ & $65 \cdot 4(11 \cdot 6)$ \\
Weight $(\mathrm{kg})$ & $1 \cdot 7(0 \cdot 6)$ & $1 \cdot 6(0 \cdot 6)$ \\
Urine volume $(1 / 24 \mathrm{~h}$ & $192 \cdot 8(76 \cdot 7)$ & $142 \cdot 8(56 \cdot 9)$ \\
Urinary sodium $(\mathrm{mmol} / 2+\mathrm{h})$ & $67 \cdot 1(25 \cdot 1)$ & $55 \cdot 7(20 \cdot 4)$ \\
Urinary potassium $($ mmol $24 \mathrm{~h})$ & $3 \cdot 9$ \\
Alcohol consumption (units week $)$ & $14 \cdot 1$ & \\
& &
\end{tabular}

coefficients between blood pressure and the variables studied. The strongest correlations for systolic pressure in both men and women were with age and body mass index, whereas for diastolic pressure the strongest correlation was with body mass index and age was less important. There was a relation between pulse rate and both systolic and diastolic pressures in men and women. There was also a weak relation between alcohol consumption and blood pressure in men but not women. The association between sodium excretion and blood pressure was weakly positive whereas
Correspondence to: Dr Smith. 
TABI.E II-Correlation coefficients hetween blood pressure and other variables in men and women

\begin{tabular}{|c|c|c|c|c|}
\hline & \multicolumn{2}{|c|}{$\operatorname{Men}(n=3754)$} & \multicolumn{2}{|c|}{ Women $(\mathrm{n}=3600)$} \\
\hline & Sỵstolic & Diastolic & Systolic & Diastolic \\
\hline Age & $0 \cdot 221$ & $0 \cdot 083$ & $0 \cdot 295$ & $0 \cdot 138$ \\
\hline Body mass index & $0 \cdot 173$ & $0 \cdot 247$ & 0.256 & $0 \cdot 259$ \\
\hline Pulse rate & $0 \cdot 168$ & $0 \cdot 192$ & $0 \cdot 130$ & $0 \cdot 158$ \\
\hline Alcohol consumption & $0 \cdot 076$ & 0.099 & -0.011 & 0.033 \\
\hline Urinary sodium & $0 \cdot 025$ & $0 \cdot 026$ & 0.055 & 0.052 \\
\hline Urinary potassium & $-0 \cdot 052$ & -0.019 & $-0 \cdot 045$ & -0.042 \\
\hline Urinary sodium:potassium & $0 \cdot 080$ & $0 \cdot 059$ & $0 \cdot 083$ & 0.086 \\
\hline Urinary sodium:creatinine & $0 \cdot 046$ & 0.008 & 0.087 & 0.076 \\
\hline Urinary potassium:creatinine & $-0 \cdot 0+4$ & $-0 \cdot 046$ & $-0 \cdot 022$ & -0.028 \\
\hline
\end{tabular}

between potassium excretion and blood pressure it was weakly negative. The relation between blood pressure and the ratio of sodium to potassium excretion was stronger than that between blood pressure and excretion of each electrolyte individually.

The variables, but not the ratios, were fitted stepwise into a multiple regression model, with both systolic and diastolic pressures, to assess the independent effects in men and women separately. Table III shows the standardised regression coefficients for each of the four models. Age, body mass index, pulse rate, and alcohol consumption all fitted positively in each model, potassium excretion fitted negatively, and sodium excretion did not enter at all.

TABLE III-Stepwise regression models of systolic and diastolic pressure in men and women

\begin{tabular}{|c|c|c|c|}
\hline \multicolumn{2}{|c|}{ Systolic blood pressure } & \multicolumn{2}{|c|}{ Diastolic blood pressure } \\
\hline Variable & $\begin{array}{l}\text { Standardised } \\
\text { regression } \\
\text { coefficient }\end{array}$ & Variable & $\begin{array}{l}\text { Standardised } \\
\text { regression } \\
\text { coefficient }\end{array}$ \\
\hline \multicolumn{4}{|c|}{ Men } \\
\hline Age & $0 \cdot 23$ & Body mass index & $0 \cdot 24$ \\
\hline Pulse rate & $0 \cdot 16$ & Pulse rate & $0 \cdot 17$ \\
\hline Body mass index & $0 \cdot 17$ & Alcohol consumption & $0 \cdot 10$ \\
\hline Alcohol consumption & 0.09 & Age & 0.09 \\
\hline Urinary potassium & $-0 \cdot 04$ & Urinary potassium & -0.03 \\
\hline $11.5 \%$ ()f variance & Explained & $11 \cdot 2 \%$ Of variance & explained \\
\hline \multicolumn{4}{|c|}{$W^{\prime}$ omen } \\
\hline Age & $0 \cdot 28$ & Body mass index & $0 \cdot 25$ \\
\hline Body mass index & $0 \cdot 23$ & Pulse rate & $0 \cdot 16$ \\
\hline Pulse rate & $0 \cdot 14$ & Age & $0 \cdot 12$ \\
\hline Urinary potassium & $-0 \cdot 04$ & Alcohol consumption & 0.06 \\
\hline Alcohol consumption & 0.03 & Urinary potassium & -0.05 \\
\hline $16.0 \%$ Of variance & explained & $11.2 \%$ Of variance & explained \\
\hline
\end{tabular}

The contribution of potassium excretion was small in all four models, and alcohol consumption played a greater part in men than women. The proportion of the variance explained by these five variables, however, was small.

\section{Discussion}

This is one of the largest studies within a community of the association between salt and blood pressure. The advantage of this approach over studies between communities is that methods of measuring blood pressure and estimating dietary salt are standardised; the ranges of dietary salt intake and blood pressure in studies between communities, however, are usually greater.

The 24 hour sodium excretion found in this study is comparable with that in other studies of the Scottish population ${ }^{11}$ and is higher than that in other European countries. $^{2} 12$ In contrast, the 24 hour potassium excretion is similar to or slightly lower than that observed in these other studies. The blood pressure is similar to that found in other European studies of the same age range. The correlation coefficients between blood pressure and the other variables showed age, body mass index, and pulse rate to be the main correlates in men and women. Alcohol consumption showed a relation with blood pressure only in men. The relation between sodium and potassium excretion was weak and of similar magnitude to that observed in other studies. ${ }^{312}$ The relation between potassium excretion and blood pressure was consistently negative.

In the stepwise multiple regression models for systolic and diastolic pressure in men and women the same five variables entered but in different orders; sodium excretion did not enter the models. Although potassium excretion entered each model, its contribution as seen by the standardised regression coefficient was small. The total variance explained in these models was also small. The effect of alcohol was greater in men than women, probably because of the lower consumption of alcohol by women.

These findings, which in general agree with those from other studies within populations, show that the association between sodium and blood pressure is weak and does not have any real independent role in explaining blood pressures. The study was large enough to detect an effect of any importance. ${ }^{x}$ That we found no independent association between sodium and blood pressure might be explained by inaccuracies in measurement of blood pressure or by the inadequacy of a single 24 hour urine collection to characterise a person's salt intake. ${ }^{7}$ The ranges of blood pressure and salt intake tend to be smaller in a study within a community, which may conceal a true association. The most likely explanation of our findings, however, is that the true association between sodium and blood pressure is extremely weak. The effect of alcohol and potassium intake on blood pressure seems greater than that of sodium and warrants further study.

We thank Dr Jan Staessen for his comments and Miss Gwen Oliphant for preparing the manuscript.

I Joosens JV, Geboers J. Salt and hypertension. Prez Med 1983;12:53-9.

2 Boon NA, Aronson JK. Dietary salt and hypertension: treatment and prevention. Br Med f 1985;290:949-50.

3 Bulpitt CJ, Broughton PMG, Markowe HLJ, et al. The relationship between both sodium and potassium intake and blood pressure in London civil servants. F ('hronic Dis 1986:39:211-9.

4 Salonen JT, Tuomilehto J, Tanskanen A. Relation of blood pressure to reported intake of salt, saturated fats and alcohol in healthy middle-aged repored intake of salt, saturated fats and alcohol in he

5 Gleibermann I. Blood pressure and dietary salt in human populations. Ecology of Food and Nutrition 1973;2:143-56.

6 Grobbee DE, Hofman A. Does sodium restriction lower blood pressure? BrMed F 1986:293:27-9.

7 Liu K, Cooper R, McKeever J, cl al. Assessment of the association between habitual salt intake and high blood pressure: methodological problems Am 7 Epidemiol 1979;110:219-26.

8 Watt GCM, Foy CJW. Dietary sodium and criterial pressure: problems of studies within a single population. I Epidemiol Community Healh 1982;36 $197-201$

9 Smith WCS, Crombie IK, Tavendale R, Irving JM, Kennicer MB, TunstallPedor $\mathrm{H}$. The Scottish heart health study: objectives and development of methods. Health Bull 1987;45:211-7.

10 Rose GA, Blackburn H, Gillum RF, Prineas KJ. Cardiovascular survey methods. Geneva: World Health Organisation, 1982.

11 Beevers DG, Hawthorne VM, Padfield PL. Salt and blood pressure in Scotland. Br Med I 1980;281:641-2.

12 Staessen J, Fagard R, Liinen P, Amery A, Bulpitt C, Joossens JV. Salt and blood pressure in Beligum. F Eipidemiol Community Health 1981;35:256-61.

Accepted 13 fuly 1988

\section{Correction}

Is dialysis hypotension caused by an abnormality of venous tone?

Several editorial errors occurred in this paper by $\mathrm{Dr}$ John $\mathrm{R}$ Bradley and others (11 June, p 1634). The penultimate sentence of the abstract should read, "The index of venous tone rose at a mean rate of $0.23 \mathrm{ml} / \mathrm{dl}$ over $40 \mathrm{~mm} \mathrm{Hg} /$ hour during dialysis with acetate fluid and $0.20 \mathrm{ml} / \mathrm{dl}$ over $40 \mathrm{~mm} \mathrm{Hg}$ /hour during dialysis with bicarbonate fluid.'

In the last line of table II the mean (SE) of difference for venous tone in forearm before dialysis should be $0.05(0 \cdot 10)$, not 0.5 $(0 \cdot 10)$

Reference 6 should be omitted from the reference list because the sentence that referred to it in the discussion was deleted. 